\title{
Skeletonized internal thoracic artery harvesting reduces chest wall dysesthesia after coronary bypass surgery
}

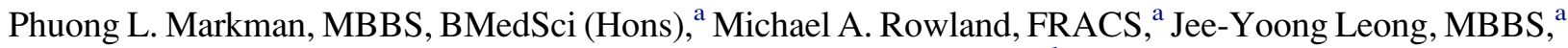 \\ Juliana Van Der Merwe, BCur, MPhil, ${ }^{\mathrm{a}}$ Elsdon Storey, DPhil, FRACP ${ }^{\mathrm{b}}$ Silvana Marasco, MS, FRACS, ${ }^{\mathrm{a}}$ \\ Justin Negri, FRACS, ${ }^{a}$ Michael Bailey, PhD, MSc (Stats), ${ }^{c}$ and Franklin L. Rosenfeldt, MD, FRACS ${ }^{\mathrm{a}}$
}

\begin{abstract}
Objective: A pain syndrome related to intercostal nerve injury during internal thoracic artery harvesting causes significant morbidity after coronary bypass surgery. We hypothesized that its incidence and severity might be reduced by using skeletonized internal thoracic artery harvesting rather than pedicled harvesting.
\end{abstract}

\begin{abstract}
Methods: In a prospective double-blind clinical trial, 41 patients undergoing coronary bypass were randomized to receive either unilateral pedicled or skeletonized internal thoracic artery harvesting. Patients were assessed 7 (early) and 21 (late) weeks postoperatively with reproducible sensory stimuli used to detect chest wall sensory deficits (dysesthesia) and with a pain questionnaire used to assess neuropathic pain.
\end{abstract}

\begin{abstract}
Results: At 7 weeks postoperatively, the area of harvest dysesthesia (percentage of the chest) in the skeletonized group $(\mathrm{n}=21)$ was less (median, $0 \%$; interquartile range, $0-0)$ than in the pedicled group $(\mathrm{n}=20)(2.8 \%[0-13]$, $P=.005)$. The incidence of harvest dysesthesia at 7 weeks was $14 \%$ in the skeletonized group versus $50 \%$ in the pedicled group $(P=.02)$. These differences were not sustained at 21 weeks, as the median area of harvest dysesthesia in both groups was $0 \%(P=.89)$ and the incidence was $24 \%$ and $25 \%$ in the skeletonized and pedicled groups, respectively $(P=1.0)$. The incidence of neuropathic pain in the skeletonized group compared with the pedicled group was $5 \%$ versus $10 \%(P=.6)$ at 7 weeks and $0 \%$ versus $0 \%(P=1.0)$ at 21 weeks.
\end{abstract}

Conclusions: Compared with pedicled harvesting, skeletonized harvesting of the internal thoracic artery provides a short-term reduction in the extent and incidence of chest wall dysesthesia after coronary bypass, consistent with reduced intercostal nerve injury and therefore the reduced potential for neuropathic chest pain. (J Thorac Cardiovasc Surg 2010;139:674-9)

Prolonged and severe chest wall pain is an occasional but troublesome complication after coronary artery bypass grafting $(\mathrm{CABG})$ involving sternotomy and harvesting of the internal thoracic artery (ITA). Affected patients have areas of numbness and/or hypersensitivity (collectively denoted $d y s$ esthesia) on the anterior chest wall; in the worst cases, severe pain is induced by everyday activities such as dressing and showering. This pain is described as neuropathic, can cause significant morbidity, and is difficult to treat. ${ }^{1}$ The incidence of such pain after CABG surgery ranges from $14 \%$ to $56 \%$, depending on the definition used and the timing of postoperative assessment. ${ }^{1-4}$ It has been postulated that this pain syndrome is caused or at least contributed to by injury (mechanical, thermal or ischemic) to the intercostal nerves

From the Cardiac Surgical Research Unit, ${ }^{\text {a }}$ CJ Officer Brown Cardiothoracic Unit, Alfred Hospital; the Department of Neurology, ${ }^{\mathrm{b}}$ Alfred Hospital, and Department of Medicine (Neuroscience), Monash University; and the Department of Epidemiology \& Preventive Medicine, ${ }^{\mathrm{c}}$ Monash University, Melbourne, Australia.

Disclosures: None.

Received for publication Dec 17, 2008; revisions received March 5, 2009; accepted for publication March 29, 2009; available ahead of print Sept 23, 2009.

Address for reprints: Franklin Rosenfeldt, MD, FRACS, Cardiac Surgical Research

Unit, The Alfred, PO Box 315, Prahran, Victoria 3181, Australia (E-mail:

f.rosenfeldt@alfred.org.au).

0022-5223/\$36.00

Copyright (C) 2010 by The American Association for Thoracic Surgery

doi:10.1016/j.jtcvs.2009.03.066 during ITA harvesting ${ }^{5}$ owing to the close proximity of the nerves to the ITA (Figure 1). In contrast, nonneuropathic pain arises from tissue damage, whether thermal, chemical, or mechanical, appropriately sensed by a normally functioning nociceptive system and subsiding as the injured tissue heals.

\section{ITA HARVEST TECHNIQUES}

Two techniques of ITA harvesting are in routine clinical use. The standard technique is pedicled harvesting whereby the ITA is harvested with a sheath of perivascular tissue comprising the internal thoracic veins, the perivascular fat pad, and a strip of endothoracic fascia (Figure 2, A). Normally, cautery is used to divide the arterial branches, potentially producing thermal injury to the intercostal nerves. In the skeletonized technique the artery is harvested in isolation, with minimal use of cautery, leaving perivascular tissue largely intact (Figure 2, B).

\section{Previous Studies}

Two previous studies have compared skeletonized and nonskeletonized ITA harvesting with respect to chest wall pain and impaired sensation; their results were conflicting. In a randomized clinical trial, Boodhwani and coworkers ${ }^{6}$ found that skeletonized ITA harvesting was associated 


\section{Abbreviations and Acronyms \\ $\mathrm{CABG}=$ coronary artery bypass grafting \\ $\mathrm{IQR}=$ interquartile range \\ ITA $=$ internal thoracic artery}

with reduced pain 3 months postoperatively and a reduction in sensory deficits 4 weeks and 3 months postoperatively. Conversely, Bar-El and coworkers ${ }^{7}$ sent screening questionnaires to patients after ITA harvesting and then assessed a subgroup of those patients clinically, finding no difference in the degree of post-CABG chest wall pain associated with skeletonized and pedicled ITA harvesting.

Skeletonized harvesting of the ITA has been proposed as a potential solution to some of the problems associated with ITA harvesting. Some of the proposed benefits include increased conduit length, ${ }^{8}$ increased conduit blood flow, ${ }^{9}$ reduced sternal hypoperfusion, ${ }^{10,11}$ reduced sternal wound infection, ${ }^{8}$ and reduced postoperative bleeding. ${ }^{8}$

\section{Hypothesis and Aims}

We hypothesized that skeletonized ITA harvesting reduces intercostal nerve injury, reflected by a reduction in dysesthesia and neuropathic pain on the chest wall. The aims of the study were to compare the extent and incidence of dysesthesia and the incidence of neuropathic pain in patients who received skeletonized with those who received pedicled ITA harvesting.

\section{METHODS}

\section{Study Design}

In a prospective randomized double-blind clinical trial, patients undergoing unilateral ITA harvest were randomized to receive either pedicled or skeletonized harvesting. Randomization was achieved with envelopes opened by the surgeon immediately before the operation. Exclusion criteria included inability to speak English, participation in other studies, and factors that could alter chest wall sensation (previous chest surgery, chest radiotherapy, or stroke). The study protocol was approved by the Alfred Hospital Ethics Committee and informed consent was obtained from patients before participation.

\section{Data Collection and Management}

Three surgeons (M.R., S.M., and J.N.) enrolled their patients in the study. Intraoperatively, the time taken to harvest the ITA was recorded, defined as the time lapsed from the insertion to removal of the ITA-harvesting sternal retractor. All the data were recorded by a nurse who ensured that neither patients nor investigator assessing the patients postoperatively had knowledge of the harvest technique used. Patients' demographics and perioperative data were retrieved from an electronic database and cardiopulmonary bypass records. Postoperative data were obtained from a review of patient files.

\section{Operative Technique}

In pedicled harvesting, after a median sternotomy, a sternal retractor (Delacroix-Chevalier; Delacroix-Chevalier, Paris, France) was used to raise one hemisternum and expose the ITA. Then, with the use of cautery, the ITA was mobilized from the anterior chest wall together with a sheath of surrounding tissue consisting of the internal thoracic veins, chest wall

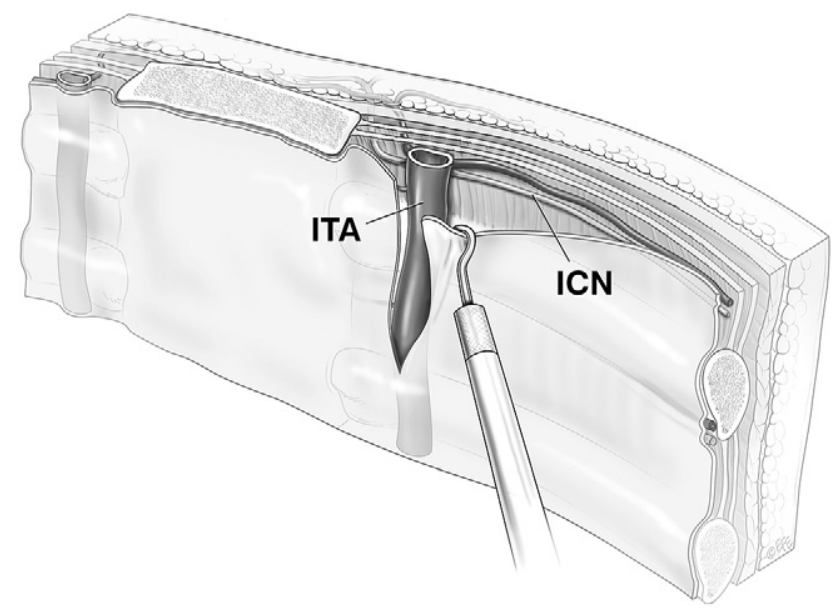

FIGURE 1. Cross section through anterior chest wall showing the close proximity of the internal thoracic artery (ITA) and its branches to the intercostal nerve $(I C N)$.

muscle, lymphatics, adipose tissue, endothoracic fascia, and parietal pleura. The largest branches were secured with hemostatic clips and smaller branches were electrocoagulated before division by cautery. In skeletonized harvesting the artery was exposed and mobilized by sharp dissection, leaving perivascular tissue intact and thereby removing the ITA in isolation. Branches were secured with hemostatic clips.

Between harvesting and grafting, both pedicled and skeletonized ITA conduits were wrapped in gauze soaked with either papaverine or glyceryl-trinitrate-verapamil solution. The ITA was clipped and divided just proximal to its bifurcation and subsequently anastomosed to a coronary artery. In all cases the sternum was closed with 3 figure-of- 8 wires.

\section{Assessing Dysesthesia by Physical Examination}

Patients were studied preoperatively and then at 7 and 21 weeks postoperatively by gloved finger palpation and nylon monofilament to assess light touch sensation and a spring-loaded device (Neurotip Pen; Owen Mumford Ltd, Oxfordshire, United Kingdom) to assess pin-prick sensation. Stimuli were applied in a systematic fashion at 2-cm intervals beginning at the right acromio-clavicular joint and proceeding across the chest, progressively downward to cover the entire chest (outlined by the clavicles, anterior axillary lines, and costal margins). When the patient indicated a point of abnormal sensation, the stimulus was applied to the abnormal point and moved radially in all directions to establish the boundary between normal and abnormal sensation, which was marked on the skin (Figure 3). These areas of abnormal sensation are referred to as the areas of dysesthesia.

Digital photographs were taken of the chest wall with the marked-out areas of dysesthesia and a scale for calibration. The photographs were analyzed with an imaging program (ImageJ 1.34s; W. Rasband, National Institutes of Health, Bethesda, Md) to quantify precisely the area of dysesthesia. The total area of the hemithorax (defined by the midline, costal margin, anterior axillary line, and clavicle) was measured by the same method, with photographs in two planes (anterior and lateral views) to correct for parallax error. The reproducibility of this technique was confirmed by taking repeated measurements in 10 test subjects and demonstrating that the coefficient of variation was only $5 \%$. Each patient's dysesthesia was expressed as a percentage area of the total area of the hemithorax, thereby standardizing for varying chest sizes.

To isolate the dysesthesia caused by ITA harvest from other causes of dysesthesia, we subtracted the area of dysesthesia on the nonharvested side from the area of dysesthesia on the harvested side. We called the resulting area difference harvest dysesthesia because it represents the dysesthesia 


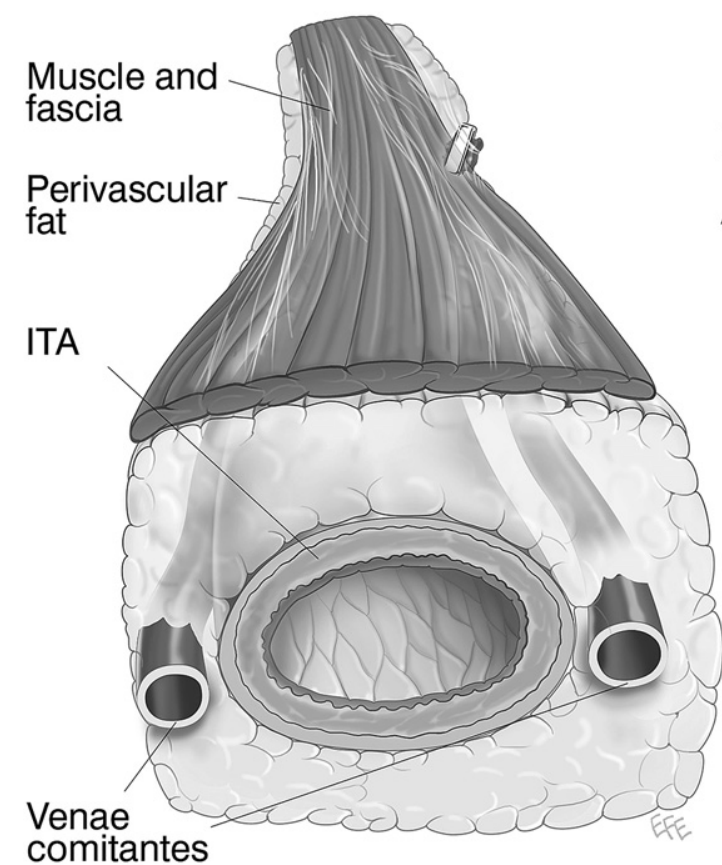

A

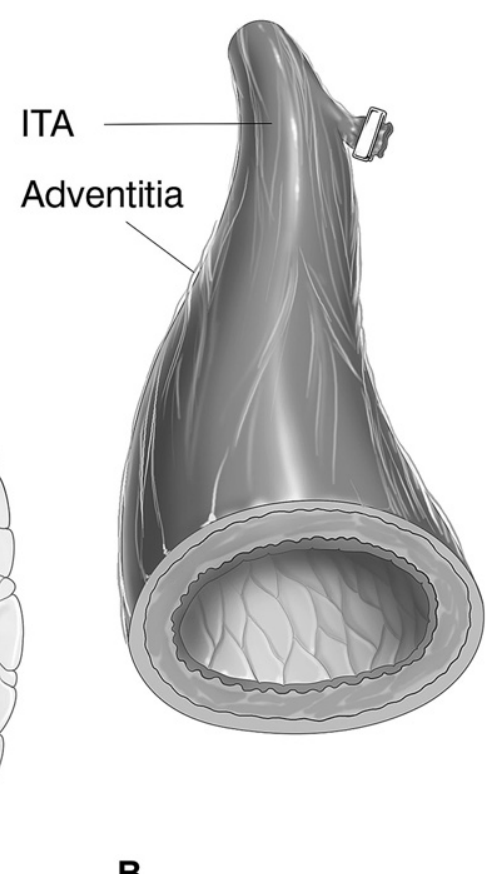

B

FIGURE 2. Pedicled (A) and skeletonized (B) techniques of internal thoracic artery (ITA) harvesting.

attributed to ITA harvesting alone. It is then possible to compare the harvest dysesthesia observed in pedicled and skeletonized groups, reducing the variability generated by non-ITA harvest causes. In terms of recording incidence, harvest dysesthesia was deemed to be present if the area of dysesthesia on the harvested side was greater than that on the nonharvested side.

\section{Assessing Chest Wall Pain by Pain Questionnaire}

At each follow-up visit, patients completed a McGill Pain Questionnaire, ${ }^{12}$ which consisted of a range of pain descriptors that helped delineate neuropathic from nonneuropathic pain. The questionnaire also included questions relating to the location of the pain, factors modifying the pain, and the impact on the patient's life. The questionnaire assessment of pain gave a measure of the symptomatic manifestation of dysesthesia whereas the physical examination provided an objective measure of intercostal nerve injury. The primary outcome variable was the area of harvest dysesthesia, expressed as a percentage of the hemithoracic area. The secondary outcome variables were the incidence of harvest dysesthesia and the incidence of neuropathic pain.

\section{Statistical Analysis and Sample Size Calculation}

Demographics, operative, and postoperative data are expressed as mean \pm standard error of the mean, and the Student $t$ test and $\chi^{2}$ test were used to compare continuous and categorical variables, respectively. The data for area of dysesthesia were not normally distributed. They were therefore expressed as median and interquartile range (IQR), with nonparametric tests used for their statistical analysis. Paired comparisons (eg, harvested versus nonharvested hemithorax) were performed by the Wilcoxon signed rank test, whereas unpaired comparisons (eg, pedicled versus skeletonized groups) were performed by the Mann-Whitney $U$ rank sum test. Statistical analysis was completed with SAS version 8.2 (SAS Institute, Inc, Cary, $\mathrm{NC}$ ). We calculated that 20 patients per group would be required to have an $80 \%$ power to detect a difference in harvest dysesthesia of $100 \mathrm{~cm}^{2}$ with an estimated standard deviation of $120 \mathrm{~cm}^{2}$ (from pilot data) and a significance level of .05 .

\section{RESULTS \\ Patients}

Between May 2002 and December 2005, 50 patients who met the inclusion criteria were consented and proceeded to CABG using the ITA. Of these, 2 were lost to follow-up

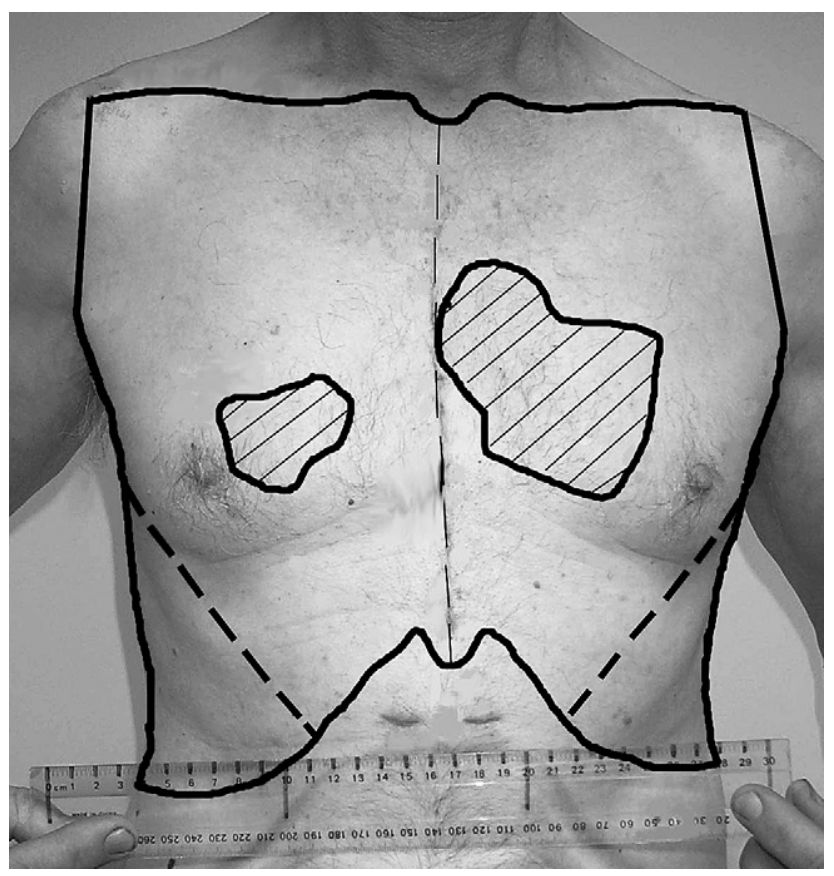

FIGURE 3. Areas of sensory impairment (hatched) on the chest wall 7 weeks after harvesting the left internal thoracic artery using the pedicled technique. 
and 7 could not return to the hospital for the follow up studies, leaving 41 in the study: 20 patients in the pedicled group and 21 in the skeletonized group. The pedicled and skeletonized harvest groups were well matched with respect to cardiovascular risk factors and disease severity indices (Table 1). Only 1 patient, a man with diabetes in the pedicled group, had any preoperative dysesthesia, affecting equally his harvested $(5.2 \%)$ and nonharvested $(6.5 \%)$ hemithoraces. There was no statistically significant difference in the operative parameters or postoperative complication rates between the 2 harvest groups (Table 1). ITA harvest duration was the same for the pedicled (29.7 \pm 6.0 minutes) and skeletonized (28.0 \pm 6.6 minutes; $P=.58$ ) harvest techniques (Table 1).

\section{Area of Harvest Dysesthesia}

At 7 weeks postoperatively, in the pedicled group the harvested hemithorax had $4.5 \%$ (IQR $0 \%-16 \%$ ) of its area affected by dysesthesia; this was significantly more than the area of dysesthesia on the nonharvested side, which was $0 \%$ (IQR, $0 \%-1.3 \% ; P=.001$ ) (Table 2). There was no corresponding difference within the skeletonized group, with $0 \%$ (IQR, $0 \%-2.5 \%$ ) on the harvested side compared with $0 \%$ (IQR, $0 \%-2.6 \%$ ) on the nonharvested side $(P=.84)$. Harvest dysesthesia (ie, harvested side minus nonharvested side) covered $2.8 \%$ (IQR, $0 \%-13 \%$ ) of the hemithorax in the pedicled harvest group, which was greater than $0 \%$ (IQR, $0 \%-0 \%)$ in the skeletonized group $(P=.005)$.

Again at 21 weeks postoperatively, in the pedicled group there was more dysesthesia on the harvested than the nonharvested hemithorax, which is observed not in the median values ( 0 on both sides) but in the IQR. The 75 th percentile was $6.1 \%$ on the harvested side versus $0 \%$ on the nonharvested side $(P=.03)$. In the skeletonized group there was no corresponding difference between harvested and nonharvested sides $(P=.43)$. In contrast to the findings at 7 weeks, harvest technique made no difference to harvest dysesthesia at 21 weeks: $0 \%$ (IQR, $0 \%-5.1 \%$ ) in the pedicled group versus $0 \%(\mathrm{IQR}, 0 \%-4.5 \%)$ in the skeletonized group $(P=.89)$.

\section{Incidence of Harvest Dysesthesia}

At 7 weeks postoperatively, the skeletonized group had a significantly lower incidence of harvest dysesthesia $(14 \%)$ than did the pedicled group $(50 \% ; P=.02$; Figure 4$)$. At 21 weeks postoperatively, the incidence of harvest dysesthesia was similar in the skeletonized group $(24 \%)$ and the pedicled group $(25 \% ; P=1.0$; Figure 4$)$. There was no significant change in the incidence of harvest dysesthesia between 7 and 21 weeks in either the pedicled group $(P=.17)$ or the skeletonized group $(P=.70)$.

\section{Postoperative Chest Wall Pain}

At 7 weeks postoperatively, $50 \%$ of pedicled and $45 \%$ of skeletonized patients reported chest pain $(P=1.0)$, but only
TABLE 1. Patient demographics, operative and postoperative data

\begin{tabular}{|c|c|c|c|}
\hline Variable & $\begin{array}{l}\text { Pedicled } \\
(\mathbf{n}=\mathbf{2 0})\end{array}$ & $\begin{array}{l}\text { Skeletonized } \\
\quad(\mathbf{n}=\mathbf{2 1})\end{array}$ & $\begin{array}{c}P \\
\text { value }\end{array}$ \\
\hline \multicolumn{4}{|l|}{ Preoperative data } \\
\hline Age, y & $69.4 \pm 9.5$ & $67.0 \pm 10$ & .40 \\
\hline Male, n (\%) & $15(75)$ & $16(76)$ & 1.0 \\
\hline Diabetic, n $(\%)$ & $5(25)$ & $5(24)$ & 1.0 \\
\hline Body mass index, $\mathrm{kg} / \mathrm{m}^{2}$ & $26.3 \pm 0.8$ & $27.1 \pm 0.9$ & .53 \\
\hline $\begin{array}{l}\text { Patients with preoperative } \\
\text { sensory dysfunction, } \mathrm{n}\end{array}$ & 1 & 0 & 1.0 \\
\hline \multicolumn{4}{|l|}{ Operative data } \\
\hline Off-pump CABG, n (\%) & $0(0)$ & $2(10)$ & .49 \\
\hline CPB time, $\min$ & $100 \pm 4.2$ & $91.3 \pm 4.4$ & .15 \\
\hline Aortic crossclamp time, min & $76.2 \pm 3.3$ & $69.6 \pm 3.8$ & .20 \\
\hline Distal anastomoses, $\mathrm{n}$ (range) & $3(1-5)$ & $3(1-5)$ & .15 \\
\hline Left ITA harvested, n (\%) & $19(95)$ & $20(95)$ & 1.0 \\
\hline $\begin{array}{l}\text { ITA harvest duration, min } \\
\text { Postoperative data }\end{array}$ & $29.7 \pm 6.0$ & $28.0 \pm 6.6$ & .58 \\
\hline In-hospital mortality, $\mathrm{n}$ & 0 & 0 & 1.0 \\
\hline Intensive care unit length of stay, $h$ & $32.8 \pm 6.8$ & $32.4 \pm 6.2$ & .96 \\
\hline In-hospital length of stay, $d$ & $7.67 \pm 0.9$ & $8.58 \pm 1.2$ & .56 \\
\hline Reoperation for bleeding, n ( $\%)$ & $2(10)$ & $1(5)$ & .60 \\
\hline Blood transfusions, n (\%) & $10(50)$ & $6(31)$ & .25 \\
\hline Chest tube drainage in $4 \mathrm{~h}, \mathrm{~mL}$ & $209 \pm 26.8$ & $210 \pm 61.0$ & .99 \\
\hline Deep sternal wound infection, $\mathrm{n}(\%)$ & $0(0)$ & $0(0)$ & 1.0 \\
\hline $\begin{array}{l}\text { Superficial sternal wound } \\
\text { infection, } \mathrm{n}(\%)\end{array}$ & $0(0)$ & $2(10)$ & .49 \\
\hline Time to first follow-up, $\mathrm{d}$ & $49.0 \pm 2.2$ & $52.8 \pm 3.0$ & .46 \\
\hline Time to second follow-up, $\mathrm{d}$ & $149 \pm 14.8$ & $150 \pm 18.2$ & .96 \\
\hline
\end{tabular}

$C A B G$, Coronary artery bypass grafting; $C P B$, cardiopulmonary bypass; ITA, internal thoracic artery.

a subset of these patients $(10 \%$ of the pedicled group and $5 \%$ of the skeletonized group; $P=.6$ ) described typical neuropathic pain. The neuropathic pain was aggravated by light touch, not movement, and was located on the harvested hemithorax in the parasternal region including part of the breast. The pain did not interfere with their activities during the day but did occasionally interfere with sleep. At 21 weeks postoperatively, the incidence of pain dropped to $10 \%$ in the pedicled group and $5 \%$ in the skeletonized group $(P=$ $1.0)$, and none of the pain was neuropathic. None of the differences between harvest groups was significant.

\section{Other Predictors of Sensory Impairment}

Other risk factors for postoperative neuropathic pain were analyzed by univariate analysis: age at time of operation, gender, diabetes, aortic crossclamp time, time taken to harvest the ITA, reoperation for bleeding, sternal wound infections, and time since the operation. None of these was a significant predictor of postoperative dysesthesia or neuropathic pain.

\section{DISCUSSION}

This randomized clinical trial showed a reduction in the area and the incidence of altered chest wall sensation early (7 weeks) but not late (21 weeks) after ITA harvesting using 
TABLE 2. Area of abnormal chest wall sensation (expressed as percentage of hemithoracic area)

\begin{tabular}{|c|c|c|c|c|c|c|c|c|c|}
\hline & \multicolumn{4}{|c|}{ Pedicled harvest $(\mathbf{n}=\mathbf{2 0})$} & \multicolumn{4}{|c|}{ Skeletonized harvest $(n=21)$} & \multirow{2}{*}{$\begin{array}{c}\text { Harvest } \\
\text { dysesthesia in } \\
\text { pedicled vs } \\
\text { skeletonized groups } \\
(P \text { value }) \\
\end{array}$} \\
\hline & $\begin{array}{c}\text { Nonharvest } \\
(\%) \\
\end{array}$ & $\begin{array}{c}\text { Harvest } \\
(\%)\end{array}$ & $\begin{array}{c}\text { Harvest vs } \\
\text { nonharvest } \\
(P \text { value }) \\
\end{array}$ & $\begin{array}{c}\text { Harvest } \\
\text { dysesthesia* (\%) }\end{array}$ & $\begin{array}{c}\text { Nonharvest } \\
(\%) \\
\end{array}$ & $\begin{array}{c}\text { Harvest } \\
(\%)\end{array}$ & $\begin{array}{c}\text { Harvest vs } \\
\text { nonharvest } \\
(P \text { value }) \\
\end{array}$ & $\begin{array}{c}\text { Harvest } \\
\text { dysesthesia* }(\%)\end{array}$ & \\
\hline $7 \mathrm{wk}$ & $0(0-1.3)$ & $4.5(0-16)$ & .001 & $2.8(0-13)$ & $0(0-2.6)$ & $0(0-2.5)$ & .84 & $0(0-0)$ & .005 \\
\hline $21 \mathrm{wk}$ & $0(0-0)$ & $0(0-6.1)$ & .03 & $0(0-5.1)$ & $0(0-4.4)$ & $0(0-10)$ & .43 & $0(0-4.5)$ & .89 \\
\hline
\end{tabular}

Values given are median (interquartile range). Boldface $P$ values indicate significance. $*$ Harvest dysesthesia $=$ dysesthesia on the harvest hemithorax minus dysesthesia on the nonharvest hemithorax.

the skeletonized technique compared with the pedicled technique. These findings were mainly explained by the trend $(P$ $=.19$ ) toward reduction in harvest dysesthesia in the pedicled group (at 21 weeks compared with 7 weeks), whereas there was no statistically significant change in the skeletonized group over the same time interval $(P=.70)$. We could speculate that some healing of nerves occurred, at least in the pedicled group, during the interval between assessments. In general, axonal regeneration occurs at a rate of 1 to $3 \mathrm{~mm}$ per day ${ }^{13}$ and recovery from acute pressure gradient-induced demyelination (as might occur with local stretch, for example) occurs over 2 to 7 months. ${ }^{14}$

The incidence of true neuropathic pain (assessed by using a pain questionnaire) was low and not different between the 2 groups at 7 weeks postoperatively and was absent at 21 weeks.

\section{Pain Mechanisms}

The objective of the present study was to determine whether altering ITA harvest technique could reduce the neuropathic pain syndrome after CABG surgery, but there are obvious difficulties in studying such a relatively uncommon complication. The mechanism thought to underlie neuropathic chest pain is injury to the intercostal nerves. However, to achieve statistical power it was prudent to study chest wall sensory abnormality (dysesthesia), which is a more common manifestation of injury to the intercostal nerves than neuropathic pain itself.

The etiology of intercostal dysesthesia (ie, nerve injury) is multifactorial and has been documented after CABG operations in which the ITA is not used and after noncardiac sternotomy. Persistent chest wall pain has been reported in $18 \%$ to $28 \%$ of patients after CABG without ITA harvesting ${ }^{7,15}$ and in $27 \%$ of patients after non-CABG sternotomy, such as thymectomy. ${ }^{16}$ It is therefore evident that ITA harvesting is not the sole mechanism for this pain. It has been suggested that spreading of the sternal retractor can buckle costal cartilages and ribs and that this rib hyperflexion might cause stretching and compression injury to intercostal nerves. ${ }^{17,18}$ When the ITA is harvested, a characteristic asymmetric distribution of dysesthesia has been documented previously. ${ }^{1,3}$ We isolated the effect of ITA harvesting from that of coexisting factors by introducing the concept of harvest dysesthe- sia. This enabled a comparison of pedicled and skeletonized harvest techniques against a noisy background of dysesthesia caused by nonharvest mechanisms.

\section{Comparison with Other Studies}

Our 7-week results accord with the findings of Boodhwani and coworkers ${ }^{6}$ that skeletonized harvesting was

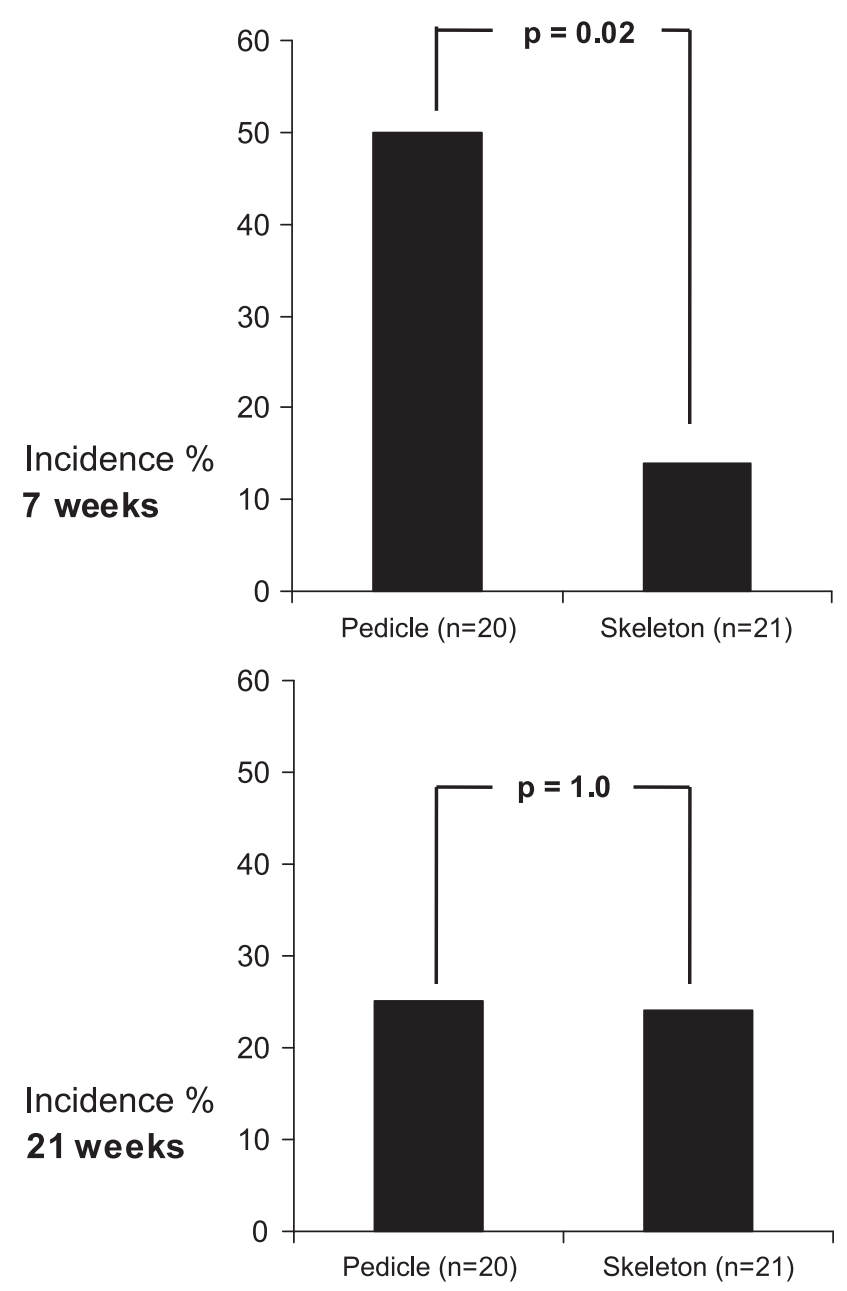

FIGURE 4. Incidence of harvest dysesthesia. The differences in harvest dysesthesia between 7 and 21 weeks for the pedicled group $(P=.17)$ and the skeletonized group $(P=.70)$ were not statistically significant. 
associated with reduced extent and incidence of sensory abnormalities in the early postoperative period. However, Boodhwani's group found a persistence of the difference at 4 months postoperatively, whereas we did not observe such a difference at 5 months. Bar-El and colleagues ${ }^{7}$ found no difference in the incidence of post-CABG pain between pedicled and skeletonized techniques, but this finding may be explained by the study design; they only examined a subgroup of patients who reported in a mail-out questionnaire that they experienced chest pain, therefore eliminating the pain-free population, who would have contributed to a more meaningful comparison of pain outcome.

\section{The Challenge of Studying Pain}

The study of pain is intrinsically difficult because an individual's pain perception is modulated by complex, interrelated factors, such as the individual's ability to describe pain, previous experiences of pain, and cultural patterns of pain tolerance. The detection of sensory impairment has more objectivity. We minimized these problems by using a robust study design (prospective, randomized, and double-blinded) and careful selection of sensory assessment tools that provided highly reproducible stimuli, were sensitive in detecting sensory change, and were both practical and valid for use on the chest wall. Further, we standardized for chest size, and for each patient we used the nonoperative side as a control.

Overlap and redundancy are features of dermatomal innervation on the chest wall, so it is likely that no sensory deficit would result from injury to a single intercostal nerve, but rather would require injury to two or more adjacent nerves. However, hypersensitivity can arise from injury to a single nerve that is sufficient to elicit central (spinal) sensitization of the nerve.

\section{Clinical Implications}

True neuropathic chest pain appears to be a severe problem in only a small proportion of patients after ITA harvesting, but this nonetheless equates to large numbers of patients globally. The choice of ITA harvest technique involves many different variables relating to the patient, properties of the conduit, and the practical constraints of the operative environment. It is therefore unlikely that any pain-related benefits of skeletonized harvesting would by itself change clinical practice, but it does add to the numerous beneficial reasons for using the skeletonized technique in preference to pedicled harvesting. The present study has highlighted the multifactorial nature of post-CABG dysesthesia and the significant contribution of ITA harvesting. In conjunction with the findings of a previous randomized clinical trial, ${ }^{6}$ this study reinforces the message that skeletonizing the ITA might reduce the incidence and severity of postoperative sensory dysfunction. Owing to its small size, the present study was not powered to answer the more important question of whether or not this translates to a reduction in true neuropathic pain, which would require a much larger study population.

\section{CONCLUSIONS}

Pedicled harvesting of the ITA is associated with postCABG sensory dysfunction and skeletonized ITA harvesting may provide a short-term reduction in its incidence and severity, which may translate to a reduction in clinically significant neuropathic chest wall pain.

We thank Mr Levent Efe for providing the illustrations in Figures 1 and 2 .

\section{References}

1. Eisenberg E, Pultorak Y, Pud D, Bar-El Y. Prevalence and characteristics of post coronary artery bypass graft surgery pain (PCP). Pain. 2001;92:11-7.

2. Eng J, Wells FC. Morbidity following coronary artery revascularisation with the internal mammary artery. Int J Cardiol. 1991;30:55-9.

3. Mailis A, Umana M, Feindel CM. Anterior intercostal nerve damage after coronary artery bypass graft surgery with use of internal thoracic artery graft. Ann Thorac Surg. 2000;69:1455-8.

4. Taillefer MC, Carrier M, Bélisle S, Levesque S, Lanctôt H, Boisvert AM, et al. Prevalence, characteristics, and predictors of chronic nonanginal postoperative pain after a cardiac operation: a cross-sectional study. J Thorac Cardiovasc Surg. 2006;131:1274-80.

5. Mailis A, Chan J, Basinski A, Feindel C, Vanderlinden G, Taylor A, et al. Chest wall pain after aortocoronary bypass surgery using internal mammary artery graft: a new pain syndrome? Heart Lung. 1989;18:553-8.

6. Boodhwani M, Lam BK, Nathan HJ, Mesana TG, Ruel M, Zeng W, et al. Skeletonized internal thoracic artery harvest reduces pain and dysesthesia and improves sternal perfusion after coronary artery bypass surgery. A randomized, double-blind, within-patient comparison. Circulation. 2006;114:766-73.

7. Bar-El Y, Gilboa B, Unger N, Pud D, Eisenberg E. Skeletonized versus pedicled internal mammary artery: impact of surgical technique on post CABG surgery pain. Eur J Cardiothorac Surg. 2005;27:1065-9.

8. Calafiore AM, Vitolla G, Iaco AL, Fino C, Di Giammarco G, Marchesani F, et al. Bilateral internal mammary artery grafting: midterm results of pedicled versus skeletonized conduits. Ann Thorac Surg. 1999;67:1637-42.

9. Deja MA, Wos S, Golba KS, Zurek P, Domaradzki W, Bachowski R, et al. Intraoperative and laboratory evaluation of skeletonized versus pedicled internal thoracic artery. Ann Thorac Surg. 1999;68:2164-8.

10. Kamiya H, Akhyari P, Martens A, Karck M, Haverich A, Lichtenberg A. Sternal microcirculation after skeletonized versus pedicled harvesting of the internal thoracic artery: a randomized study. J Thorac Cardiovasc Surg. 2008;135:32-7.

11. Cohen AJ, Lockman J, Lorberboym M, Bder O, Cohen N, Medalion B, et al. Assessment of sternal vascularity with single photon emission computed tomography after harvesting of the internal thoracic artery. $J$ Thorac Cardiovasc Surg. 1999; 118:496-502.

12. Melzack R. The McGill Pain Questionnaire: major properties and scoring methods. Pain. 1975;1:277-99.

13. Hall S. Mechanisms of repair after traumatic injury. In: Dyck PJ, Thomas PK, eds Peripheral neuropathy. 4th ed. Philadelphia: Elsevier Saunders; 2004.p.1403-33.

14. Rudge P, Ochoa J, Gilliat RW. Acute peripheral nerve compression in the baboon: anatomical and physiological findings. J Neurol Sci. 1974;23:403-20.

15. Meyerson J, Thelin S, Gordh T, Karlsten R. The incidence of chronic post-sternotomy pain after cardiac surgery- a prospective study. Acta Anaesthesiol Scand. 2001;45:940-4.

16. Kalso E, Mennander S, Tasmuth T, Nilsson E. Chronic post-sternotomy pain Acta Anaesthesiol Scand. 2001;45:935-9.

17. Greenwald LV, Baisden CE, Symbas PN. Rib fractures in coronary bypass patients: radionucleotide detection. Radiology. 1983;148:553-4.

18. Todd DP. Poststernotomy neuralgia: a new pain syndrome [letter]. Anaesth Analg. 1989;69:81-2. 